\title{
Oldest animal sperm found inside fossilized worm cocoon
}

Preserved 50-million-year-old cell remains may give clues to evolution of earthworms and leeches.

\section{Sam Wong}

15 July 2015

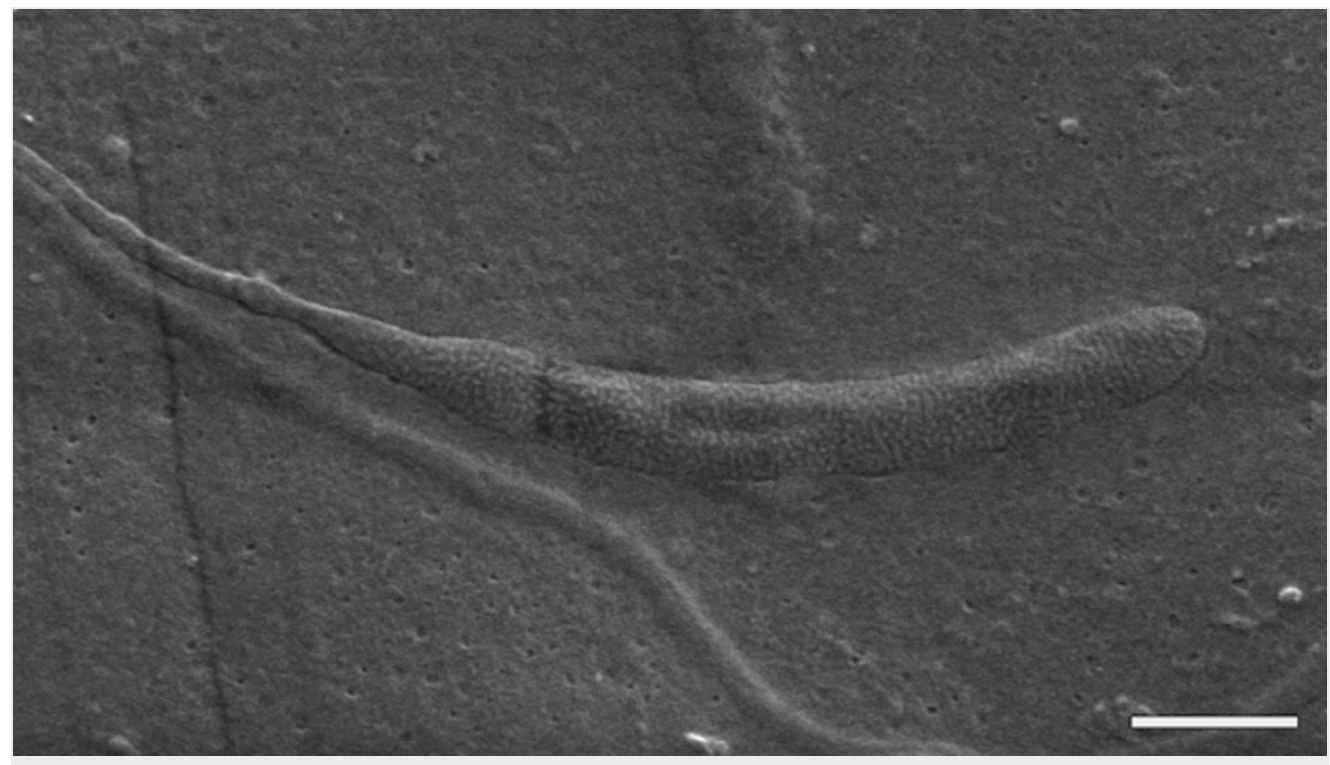

Dept Palaeobiol./Swedish Museum of Natural History

A fossilized spermatozoon fragment; the scale bar is 1 micrometre long.

The remains of long, thin cells preserved inside the 50-million-year-old fossilized cocoon of an unknown worm species represent the oldest animal sperm ever found, say researchers at the Swedish Museum of Natural History in Stockholm.

Benjamin Bomfleur and his colleagues spotted the sperm fragments when they used an electron microscope to examine the inner surface of the cocoon fossil, which had been collected by an Argentinian expedition on Seymour Island, which lies off the Antarctic Peninsula. Their findings are published today in Biology Letters ${ }^{1}$.

Because of their delicate nature, sperm cells are very rarely found in fossils. The previous oldest animal sperm was from springtails preserved in Baltic amber, about 40 million years old ${ }^{2}$. (Plant sperm fossils go back further, to 400 -million-year-old specimens from early land plants in Scotland ${ }^{3}$.)

\section{Surprising discovery}

Bomfleur says that the discovery was a surprise - "we laughed", he says, on seeing the microscope images - "but in retrospect, it makes sense that you would find them as common inclusions in fossil 
cocoons". The cocoons are secreted by some worms, including earthworms and leeches, which deposit sperm and eggs inside. Each cocoon then hardens to form a protective case for the developing embryos.

The researchers do not know what kind of worm left the sperm. Scanning electron microscope images show helical structures resembling drill-bits and beaded tails, which are characteristic of sperm produced by crayfish worms, leech-like creatures that live on freshwater lobsters. But these animals are found only in the Northern Hemisphere, so it would be surprising if they had existed in Antarctica 50 million years ago, Bomfleur says. "It could be an extinct relative with similar types of sperm."

There will be no extractable DNA left in the sperm fragments, Bomfleur adds, because the chemical make-up of the organic material would have changed from its original composition over such a long time. But his team expect that the cells they saw under the microscope are not merely mineralized outer casts of the original cell's shape, but will retain their inner structure.

\section{Taxonomic tool}

The structure of sperm cells has been studied for decades as a way of determining evolutionary relationships between worm species. The team did not have access to ultra-high-resolution instruments that might reveal more detail about the sperm's microstructure than can be seen under the electron microscope. But if the fine structure of sperm is commonly preserved inside cocoons and can be imaged, Bomfleur thinks that future studies could provide important insights into the evolution of the kinds of worms that secrete cocoons. "If it should turn out that we can get this information, all of a sudden we would basically unlock an entire fossil record for a group that hardly had any identifiable fossils before," he says. Soft-bodied microorganisms that do not usually fossilize, including nematodes ${ }^{4}$, have also been found preserved inside cocoons, but few researchers have studied them.

Jakob Vinther, who studies invertebrate evolution at the University of Bristol, UK, agrees that cocoon fossils could represent an underexplored avenue for understanding the origin of earthworms and leeches. "I think we might have a really interesting system here that can be sort of a hidden window to the past," he says. "There could be a lot of potential hidden gems inside those cocoons."

Nature | doi:10.1038/nature.2015.17976

\section{References}

1. Bomfleur, B., Mörs, T., Ferraguti, M., Reguero, M. A. \& McLoughlin, S. Biol. Lett. 20150431 (2015).

2. Poinar, G. Hist. Biol. 14, 229-234 (2000).

3. Kerp, H., Trewin, N. H. \& Hass, H. Trans. R. Soc. Edinb. Earth Sci. 94, 411-428 (2003).

4. Manum, S. B., Bose, M. N., Sayer, R. T. \& Boström, S. Zool. Scr. 23, 27-31 (1994).

\section{SPRINGER NATURE}

